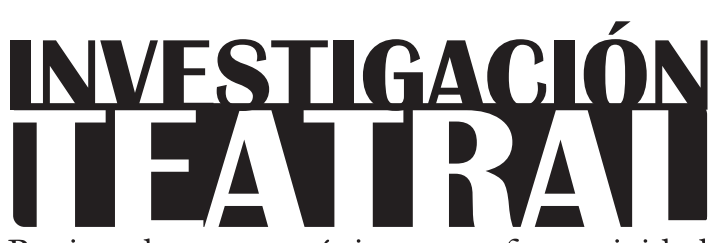

Revista de artes escénicas y performatividad

Vol. 9, Núm. 14

octubre 2018-marzo 2019

Segunda época

ISSN impreso: 1665-8728

ISSN electrónico: 2594-0953

Universidad Veracruzana

\title{
Personajes y representación en un coloquio conventual novohispano del siglo XVIII
}

Abel Rogelio Terrazas*

\footnotetext{
" Facultad de Antropología, Universidad Veracruzana, México.

e-mail: ablete7@hotmail.com
}

Recibido: 27 de abril de 2018

Aceptado: 15 de junio de 2018 
INVESTIGACIÓNTEATRAL

Revista de artes escénicas y performatividad

Vol. 9, Núm. 14

octubre 2018-marzo 2019
Personajes y representación en un coloquio conventual novohispano del siglo XviII

Abel Rogelio Terrazas

\title{
Personajes y representación en un coloquio conventual novohispano del siglo XVIII
}

\section{Resumen}

El siguiente trabajo hace un análisis de los personajes del coloquio conventual novohispano Coloquio religiosísimo dedicado al dulce Nombre de Jesús, así como de algunos elementos espectaculares importantes para su representación y de algunas condiciones y posibilidades artísticas del teatro de monjas desde la perspectiva del concepto de la "ciudad letrada", de Ángel Rama. El coloquio conventual posee rasgos dramáticos que demuestran el conocimiento de la tradición teatral desarrollada en el interior de los conventos y las exigencias ideológicas canalizadas de manera sistemática. El análisis ha permitido observar cómo, desde la parodia, la burla y el humor, el teatro novohispano generó espectáculos ingeniosos en espacios sumamente regulados, tales como los conventos de carmelitas descalzas.

Palabras clave: Barroco hispanoamericano, teatro conventual, conventos femeninos, ciudad letra$d a$, teatro novohispano, personajes-tipo.

\section{Characters and Representation in an 18th Century Conventual Colloquium from the New Spain}

\begin{abstract}
This article analyzes a religious conventual Colloquium from the New Spain, dedicated to the Sweet Name of Jesus. The characters, the representational elements, the conditions, and the artistic possibilities of the "theater of nuns" are considered from the perspective of Angel Rama's "literate city" concept. The dramatic features of this piece attest to the advanced theatrical tradition that developed within convents' walls, and the systematic way in which ideological demands were channeled. The analysis shows how using parody, mockery and humor, the theater of the New Spain offered ingenious shows in highly controlled places, such as the convents of the Discalced Carmelites.
\end{abstract}

Keywords: Hispanic-American baroque, Convent Theater, female convents, literate city, theater of the New Spain, character types. 


\section{Personajes y representación en un coloquio conventual novohispano del siglo XVIII}

U na de las notas más sobresalientes del barroco en Hispanoamérica es la vena picaresca que convierte en temas de burla a los dolores físicos, ofrece una versión cómica de las tensiones sociales y exhibe la precariedad de las instituciones, incluidos los conventos de monjas. Cuando tratamos con algunas obras conventuales costumbristas del siglo XVIII originarias de la Nueva España, los personajes femeninos se caracterizan por ciertas libertades expresivas frente a las mujeres en el hábito de religiosas: interpelan, insinúan, aluden, provocan y, en ocasiones, señalan -varios percances "impropios" de la vida conventual que, debemos comprender, serían propios solamente al quedar introducidos y mediados por las representaciones- ${ }^{1}$ La cara o faceta que nos ofrece esta vertiente del teatro conventual

1 El espectro conocido del teatro conventual hispanoamericano se ha ido ampliando, ya que actualmente se consideran todas aquellas manifestaciones escénicas de las que hay pruebas directas: obras recientemente publicadas y estudiadas (Parodi, "Teatro de monjas" y "Las obras menores"; Guillén Baca, "Ocho piezas devocionales"; Arellano y Eichmann, Entremeses, loas y coloquios; Lavrin y Loreto López, Diálogos espirituales; Sten y Gutiérrez Estupiñán, No solo ayunos...; Luciani, "Fantasmas en el convento"; Farré Vidal, Festín plausible); así como indirectas, en reseñas y crónicas de viajeros o visitantes a los conventos de la época como fray Antonio de Ciudad Real, siglo Xvi; Thomas Gage, siglo XviI; Giovanni Francesco Gemelli Careri, siglo xviII, y Manuel Romero de Terreros, insigne historiador de principios del siglo xx, quien recogió algunas relaciones sobre los festejos en los conventos. También hay que incluir el valioso estudio de Maya Ramos Smith, Censura y teatro novohispano, cuya base es la documentación resguardada primordialmente por la Inquisición en México. El coloquio que analizo en este trabajo pertenece a la edición de María Sten y Raquel Gutiérrez Estupiñán (No solo ayunos y oraciones. Piezas teatrales menores en conventos de monjas [siglo XVIII] 87-96), obra estudiada antes en la tesis de licenciatura de Víctor Jesús 
INVESTIGACIÓNTEATRAL

Revista de artes escénicas y performatividad

Vol. 9, Núm. 14

octubre 2018-marzo 2019
Personajes y representación en un coloquio conventual novohispano del siglo XVIII

Abel Rogelio Terrazas

constituye una expresión opuesta a la visión oficial, cortesana y devocional de los conventos; una perspectiva sintonizada con el tono de las burlas, ironías y sátiras que -expresadas con rasgos de "crueldad o grosería" - estaban en boga en parte de la literatura de la época. Sabido es que la vena picaresca del Barroco de Indias incluye sátiras y burlas alimentadas por la idea de "el mundo como teatro", "como una feria de farsantes, vestidos de trajes y personalidades falsas, [que] desfila en su larga galería de caricaturas"; la obra del peruano Juan de Caviedes es un buen ejemplo al respecto (Picón Salas 115-116).

En congruencia con el estudio de esta faceta picaresca en el contexto de las regulaciones monacales, en este trabajo se observa el ordenamiento de la ciudad virreinal conforme a las representaciones sociales de los personajes-tipo, desde la perspectiva de la "ciudad letrada" concebida por Ángel Rama. La "ciudad letrada" constituye una visión "sumaria" enmarcada en la "crítica de la industria cultural" de Adorno y Horkheimer. Recibió influencia del pensamiento de Martí, Henríquez Ureña y el mismo Picón Salas (Moraña, Ángel Rama 139-144). Varios estudiosos se han encargado de colocar el concepto en perspectiva, a partir de lo cual derivaron valiosas oportunidades para el análisis de acuerdo con sus intereses y objetivos. En este caso he decidido adoptar la idea de la ciudad letrada como plataforma para el análisis de los personajes-tipo y su caracterización dramática -implícita y explícita- proyectada en un escenario ubicado en un espacio sumamente regulado: el convento. Se trata de una propuesta que se articula a uno de los "vecindarios" de la ciudad letrada, "el problema de la representación y su vinculación a prácticas autorreflexivas" (Castro 126), esto es, al convento como espacio de la representación y a las adaptaciones de los modelos dramáticos que ahí existieron.

El estudio sistemático de las piezas descubiertas recientemente en los conventos (ver Nota 1 de este trabajo), de su ubicación en la serie literaria y de su funcionamiento en los espacios de representación correspondientes, irá aportando mayor conocimiento a la historia del teatro en Hispanoamérica. La vindicación de las monjas en la cultura mexicana es indispensable, ya que fueron educadoras de las mujeres de las clases dirigentes y modeladoras de conducta para todas las clases sociales. En ninguna otra figura política y religiosa es posible destacar tan claramente la conciencia de subalternidad imbricada con la de privilegio (las monjas se sabían vinculadas con el poder y al mismo tiempo asumían las implicaciones, limitantes y condiciones derivadas de sus compromisos). Como ejemplo de esta doble conciencia, algunas obras dramáticas dan cuenta, en clave humorística, de la relación entre las monjas y los encargados de escribir para ellas; se trata de obras que satirizan el

Guillén Baca, titulada "Ocho piezas devocionales inéditas del teatro carmelita (Siglos XVIII-XIX)" (156164). Me he basado en la edición de Sten y Gutiérrez Estupiñán, por razón de la claridad en la edición y porque las investigadoras incluyeron obras dramáticas de otras órdenes religiosas. 
INVESTIGACIÓNTEATRAL

Revista de artes escénicas y performatividad

Vol. 9, Núm. 14

octubre 2018-marzo 2019
Personajes y representación en un coloquio conventual novohispano del siglo XviII

Abel Rogelio Terrazas

oficio del "poeta de monjas", dibujándolo como un improvisador ingenioso. Es importante subrayar lo anterior porque, en el orden oficial para la producción escrita, no había posibilidades para la práctica del teatro al interior de los conventos. Así, encontramos un discurso barroco que reelabora un motivo cómico del teatro breve, donde los personajes fingían la ausencia de un argumento para divertir al público.

En el teatro conventual se reelabora este motivo con el fin de eludir el hecho de que ellas, las monjas, escribían también obras. La sátira de la figura del poeta de monjas o de la costumbre de recurrir a escritores por encargo, permite comprender que la práctica fue frecuente y detonaba diversión; simultáneamente, recurrían al mismo motivo como estrategia retórica para quedar absueltas. En la medida en que se llegue a conocer cómo las monjas vivieron esa realidad ambivalente, paradójica y desigual, será posible trascender el panorama del modelo que promovieron a través de sus escritos, que sigue vivo hasta la fecha.

El teatro conventual no se reduce a un registro del modelo de conducta de las monjas, es también un legado artístico que merece ser estudiado desde sus propios parámetros estéticos. De este modo será posible comprender por qué la imagen seria y recatada de las monjas convive directa o indirectamente con el registro paródico de los graciosos. Según veremos, se sostiene una imagen regulada de las monjas frente a personajes caracterizados con rasgos kinésicos y paraverbales vinculados ideológicamente con lo bajo y lo pecaminoso. Pero las monjas también conviven con la libertad y la risa que, escénicamente, las envuelve como espectadoras, personajes y actrices.

La hipótesis de este estudio es que el teatro breve conventual del siglo XviII, a razón de la elaboración de personajes-tipo americanos, contribuyó al afincamiento del poder virreinal mediante la ordenación de cuadros sociales representativos, esgrimiendo algunas estrategias retóricas propias de los géneros breves auriseculares y una comicidad adaptable y ambigua. En la ciudad había un cuerpo social especializado en ordenar la monarquía absoluta, una poderosa articulación letrada, la única capaz de manejar los lenguajes simbólicos de la hegemonía "en directa subordinación de las metrópolis" (Rama, La ciudad letrada 24). La ciudad letrada cumple su misión en el orden de los signos y "por su implícita calidad sacerdotal, contribuyó a dotarlos de un aspecto sagrado, liberándolos de cualquier servidumbre con las circunstancias" (25). Se trata de una pléyade de "religiosos, administradores, educadores, profesionales, escritores y múltiples servidores intelectuales; todos manejaban la pluma, estaban estrechamente asociados a las funciones del poder" (ibíd.). El elemento crucial del carácter cerrado, autónomo y autosuficiente de este grupo es que no tuvieron compasión de los analfabetos. ${ }^{2}$ Acerca de ello, Rama advierte:

2 Rolena Adorno matizó el concepto de signo en relación con la ciudad letrada, proponiendo una visión menos unánime del poder de los letrados; pues — señala — había "prácticas y mentalidades que no forma- 
INVESTIGACIÓNTEATRAL

Revista de artes escénicas y performatividad

Vol. 9, Núm. 14

octubre 2018-marzo 2019
Personajes y representación en un coloquio conventual novohispano del siglo XviII

Abel Rogelio Terrazas

[...] son los trescientos poetas que según Bernardo de Balbuena concurrieron al certamen de fines del siglo xvi en que él fue distinguido o el alto número de los que un siglo después recogió Sigüenza y Góngora en su Triunfo parténico. Tales cifras no guardan relación con los potenciales consumidores, y de hecho productores y consumidores debieron ser los mismos funcionando en un circuito doblemente cerrado, pues además de girar internamente, nacía del poder virreinal y volvía laudatoriamente a él ( $L a$ ciudad letrada 26).

La ciudad letrada, desde el punto de vista de este trabajo, es un concepto comprensivo que, si bien ha sido criticado por ser posiblemente reduccionista, ${ }^{3}$ permite articular algunos presupuestos teóricos con el fin de valorar las obras conventuales. El primer presupuesto es el ordenamiento discursivo que supone el concepto, más allá de la concepción del signo de raíz saussureana: la dicotomía ciudad ordenada/ciudad real, cuyo origen fue, de acuerdo con la crítica reciente a la obra de Rama, el abismo insalvable entre lengua y habla. Pues, en segundo lugar, a juicio de Román de la Campa, Rama "propone la historia como una tarea de desmontaje continuo de textos claves, particularmente literarios o filosóficos" ("El desafío” 35). Desde esta perspectiva es posible comprender cualquier tipo de alusión o interpelación hacia "lo social", en los textos literarios, como una limitación. Esta limitación nace no de la precariedad de la expresión literaria y la escritura en general, sino de entender lo social como un exceso de sentido, que siempre tendrá algo de intraducible en el discurso escrito. Por ende, las representaciones sociales a las que se alude con los personajes constituyen "puntos nodales" donde ocurren:

ban un solo discurso ideológico, sino que eran polivocales" y conformaban "un laberinto de rivalidades ideológicas" ("La ciudad letrada y los discursos" 4). El concepto de ciudad letrada es útil para el estudio de la producción de escritores marginales (5) y con bastante éxito, como demuestra Adorno, en los dos casos analizados: Francisco Núñez Muley y Felipe Guaman Poma de Ayala, comprendidos como productores de "escritos de lo imposible", dadas las condiciones y relaciones que establecieron desde situaciones y espacios distintos, pero semejantes por encontrarse bajo la mirada articuladora lenguaje/poder (9). Sin embargo, Adorno coincide plenamente con Rama al señalar que la ciudad letrada obstaculizó de manera sistemática la alfabetización de los amerindios, como una estrategia de control "que revela la importancia del lenguaje en relaciones de dominación" (22) por parte de las élites. Con todo, el modelo de análisis ofrecido por Rama -concluye Adorno- permite destacar relaciones y enlaces entre los barrios o vecindarios de la ciudad letrada en su lucha por y desde el orden de los signos, que era la vía más preciada, aunque no la única, de sobrevivencia y existencia en el contexto de la época.

3 Se trata de "una lectura canónica" de la ciudad letrada en sus relaciones con el poder, que deja fuera las versiones contrahegemónicas, las voces de los estratos sociales de marginalidad y otras modalidades discursivas que podían estar fuera de la palabra escrita (Moraña, Políticas de la escritura 169). 
INVESTIGACIÓNTEATRAL

Revista de artes escénicas y performatividad

Vol. 9, Núm. 14

octubre 2018-marzo 2019
Personajes y representación en un coloquio conventual novohispano del siglo XVIII

Abel Rogelio Terrazas

conflictos de intereses culturales, políticos y económicos; [que] no se prestan solamente a la observación distante -cronológica y espacialmente- desde posiciones estables amparadas por la institucionalidad académica; $y$, sobre todo, no conducen a un deslizamiento conceptual que neutralice las diferencias entre lo literario, lo escritural, la epistemología y lo social bajo el mismo rótulo de textualidad o discursividad ("El desafío" 42).

Los personajes son afianzamientos de la ciudad letrada, domesticaciones de las diferencias (sociales, económicas, morales, etcétera), a la luz de la caracterización dramática en el teatro. Son negociaciones y -en este caso- también caricaturizaciones, por tratarse de teatro breve. No se trata, pues, de una lectura mimética de la ciudad letrada -versus la ciudad real- en lo concerniente al nodo social o representación colectiva de los personajes. Se trata de una mediación retórica y performativa tanto en el escenario como en los textos dramáticos. En los personajes del teatro conventual, como en buena parte del teatro novohispano, aparecerán los rasgos de la plebe indistinta (el demos mexicano, de acuerdo con Rama, conformado étnicamente por lo "mestizo-mulato") que necesitaba regularse bajo motes tales como indios, payos y mulatas; aprovechando, para su identificación y ordenamiento, las expresiones tradicionales y lengua de la cultura local. Pero el proceso sería también a la inversa: los personajes son puntos de vista reflexivos acerca de las regulaciones monacales, de los acontecimientos domésticos y de la imagen de las monjas, que de ninguna manera agotan ninguna de esas relaciones identitarias.

En este sentido, ha sido pertinente entender el teatro conventual en relación con el orden advertido por Rama, tanto en La ciudad letrada como en un ensayo anterior, "La señal de Jonás sobre el pueblo mexicano". El ordenamiento propuesto por Rama implica una negociación ideológica que incluye los rasgos del suelo americano desde la perspectiva de las élites y conforma, al mismo tiempo, un doble registro social-lingüístico:

Las despectivas descripciones que de la "gente menuda" nos ha dejado la clase superior novohispana son pasibles de relectura crítica desde nuestra perspectiva, la cual nos autoriza a descubrir sintomáticos rasgos de comportamiento: ante todo, la libertad operativa de quienes no se sienten concernidos por el orden vigente, pues no pueden o no quieren aceptarlo; luego, la energía con que disputan su espacio propio, sin pararse mucho en los preceptos de la ley o de la moral, revelando codicia, empuje y desaprensión; por último, una espontánea imitación del real funcionamiento de los estratos superiores, aunque no de sus aparatosas proposiciones doctrinales, las que, como ya antes habían hecho los indios, vieron claramente desglosadas de los actos cotidianos de los señores (“La señal de Jonás” 20). 
INVESTIGACIÓNTEATRAL

Revista de artes escénicas y performatividad

Vol. 9, Núm. 14

octubre 2018-marzo 2019
Personajes y representación en un coloquio conventual novohispano del siglo XviII

Abel Rogelio Terrazas

La prevaricación idiomática, el sayagués del modelo entremesil español, se convierte en América en el "tamiz literario" del habla de la plebe, a quien el público de las obras debía identificar de inmediato. ${ }^{4}$ Esta visión reflexiva permite superar la relación dicotómica entre el convento y el resto de la sociedad, si se observan las recreaciones desde el "el tamiz literario", desde la perspectiva de las élites, de lo que ellos creyeron conveniente unificar y modelar.

Los personajes de las obras conventuales expresaron la superioridad moral y espiritual de las monjas y éstas encontraron una versión cómica, una "di-versión" de sí mismas con el fin de amenizar la vida de clausura. Por tanto, la ambigüedad dramática del personaje consiste no en ofrecer un pedazo de la circunstancia aludida, ni mucho menos un registro verídico de un determinado momento histórico; ofrecen, más bien, una inversión de valores pactada de antemano y de manera convencional frente al orden moral, social y político con fines de entretenimiento. A propósito, es oportuno suscribir un concepto de personajes-tipo del teatro breve que:

[...] por su sencillez y su esquematismo [...] preexisten a su actividad escénica, poseen un carácter convencional y repetitivo. Los tipos poseen unos rasgos caracterológicos fijos, reconocibles e inmediatamente identificables por el público. Los rasgos caracterizadores de los tipos condicionan su comportamiento y el papel que desempeñan con respecto a una posible progresión dramática. En la obra actúan en estricta conformidad con la imagen que el público tiene de ellos y no se apartan de dicho comportamiento. La deformación caricaturesca y el exceso forman parte de sus rasgos compositivos, porque se perfilan con trazos rápidos y sin ningún matiz. En el llamado género chico, por ejemplo, el guardia es gallego, el militar patriota y el alguacil corrupto [...]. No están individualizados, de no ser por su onomástica, no evolucionan siguiendo un desarrollo dramático y no se puede decir que sus parlamentos sean diálogos, sino más bien monólogos cruzados, prefijados también por la convención genérica. Así, para los entremeses del siglo XVII, los personajes son tipos en virtud de su carácter tradicional, procedente bien sea del folklore, bien sea de la literatura. [...] La perma-

4 Si bien el análisis de Rama, en tal ensayo, se finca en el corpus conformado por algunos Coloquios de Fernán González de Eslava y en múltiples manifestaciones de la ley escrita, emitida por las autoridades máximas, es necesario realizar un viraje cuando tratamos con obras influidas por la Comedia Nueva. Hay, por tanto, una tendencia orientada a dar el mayor movimiento posible al espectáculo en demérito de las tres unidades. Tratamos con un espectáculo ceremonial donde, sin excluir del todo la devoción, se enfatiza la regulación moral de las monjas; a propósito pueden observarse algunas características, en Rivera Krakowska y Terrazas (“Comunidades, monjas y teatro” 30). 
INVESTIGACIÓNTEATRAL

Revista de artes escénicas y performatividad

Vol. 9, Núm. 14

octubre 2018-marzo 2019
Personajes y representación en un coloquio conventual novohispano del siglo XVIII

Abel Rogelio Terrazas

nencia se da en virtud de la reiteración de los rasgos que los perfilan de obra en obra (Martínez López 160-161).

En el Coloquio del noviciado al Dulcísimo Nombre de Jesús (Sten y Gutiérrez Estupiñán 87-96) es de interés especial la auto-representación del convento como "vecindario" de la ciudad letrada, en función de la solicitud de obras de encargo a escritores de la ciudad. Asimismo, la obra adaptó una glosa en décima espinela, cuyo modelo tenía una larga trayectoria en América y una canción tradicional con el fin de dar cuerpo al festejo, caracterizar a los personajes y permitir la cabal representación social del convento. Lo anterior da cuenta de la versatilidad del teatro conventual para asimilar distintos recursos y armonizarlos en las representaciones, generando morfologías proteicas propias.

Estamos ante una pieza escenificada por las novicias del Convento de Santa Teresa La Antigua, de la Orden de Carmelitas Descalzas de la Ciudad de México. ${ }^{5}$ Antes de la toma de profesión, las mujeres debían pasar un año en calidad de novicias, observando un comportamiento adecuado en comunidad; en caso de que ingresaran como monjas de velo blanco, debían esperar dos años. La aceptación o rechazo era tomada por las monjas del consejo, todas de velo negro, quienes emitían la decisión final. La única monja que profesó en este convento al año siguiente de la representación del coloquio fue Ana Josefa de la Purificación, en 1766, hija de Felipe Pardo y María Teresa del Moral. De acuerdo con Josefina Muriel, el convento estuvo apegado rigurosamente a las reformas de Santa Teresa, "no sabía de mitigaciones, ni de suavidades", y estuvo reservado para españolas y criollas (Conventos de monjas 598; 367). Además:

Sólo los acontecimientos religiosos turbaron su silencio: las profesiones, las fiestas titulares y otras, como por ejemplo, la colocación del famosísimo Cristo de Ixmiquilpan, o las visitas de los virreyes y arzobispos, hacían sonar a par que las campanas las voces alegres de sus monjas, haciendo notable entonces que tras los muros monacales existía la vida (375).

Tenemos, por tanto, un coloquio de notable mixtura entre lo devocional y el humorismo, tanto por el espacio de la representación como por el hecho de ser "ejecutado" por las novicias que serían instruidas mediante la obra y quienes posiblemente esperaron años para ser

5 Llamado desde su fundación Convento de San José por estar dedicado a ese santo patrono en 1616, su nombre cambió en 1684 cuando se construyó una Iglesia aledaña dedicada a Nuestra Señora de la Antigua y el pueblo comenzó a llamarle Convento de Santa Teresa La Antigua (Muriel, Conventos de monjas 375). 
INVESTIGACIÓNTEATRAL

Revista de artes escénicas y performatividad

Vol. 9, Núm. 14

octubre 2018-marzo 2019
Personajes y representación en un coloquio conventual novohispano del siglo XviII

Abel Rogelio Terrazas

aceptadas o, caso más probable, permanecieron en el estatus de "niñas" en el interior del convento. El primer elemento importante para su representación teatral era que el carácter entremesil de la primera parte se articula en los discursos escénico y diegético de la segunda y tercera sección, la del elogio. En el nivel escénico, los cuatro personajes de la obra son tan significativos como el escritor burlado; en el nivel diegético, simbolizan la unión de sectores populares y monjas cohesionados, o adoctrinados, por el tema devocional. Estamos ante un teatro ceremonial en el que se articulan, como con una bisagra, realidad y ficción. ${ }^{6}$ Es posible que antes de la obra se pronunciara un sermón sobre el tema devocional que amplía el coloquio. Nuestra posición sobre la autoría de la obra es que sí fue escrita por un escritor de encargo, no porque la pieza esté escrita con irregularidades ni porque resulte satirizado el "poeta de monjas", sino porque su expectativa es adoctrinante y didáctica.

Las obras conventuales denominadas "coloquios" plantean, además del problema de la autoría, el de su rica configuración interna: una mezcla de elementos cultos y populares puestos en boga por la Comedia Nueva. Si bien es cierto que por Comedia Nueva se comprende el espectáculo comercial de finales del siglo XVI, para el caso del teatro de convento la influencia no se hizo esperar (a través de la mezcla de elementos cultos y populares, la polimetría y el indispensable componente cómico); sobre todo, a partir de la segunda mitad del siglo XVII, en concordancia con los principios estipulados para el ejercicio dramático en espacios y contexto religiosos: entretener y enseñar (Arellano, "La risa en las comedias" 7; Alarcón 247-272). Como teatro de circunstancia, el coloquio implicaba el funcionamiento preciso de cada elemento en armonía con la laude o la celebración cívico religiosa donde se integraba.

Josefina Muriel consigna que las Carmelas Criollas estaban bajo la jurisdicción directa del arzobispo, como lo estaban la mayor parte de los conventos de monjas (Muriel, Conventos de monjas 367; Martínez Cuesta 610). El coloquio que nos ocupa se representó el segundo domingo después de la Epifanía (día destinado a la celebración del Dulce Nombre de Jesús), momento en el que Manuel José Rubio y Salinas estaba en el poder arzobispal (1749-1765). Se trataba de un clérigo célebre por sus labores sociales, promotor educativo y de carácter afable (Sosa 182-191), aunque murió en julio de ese año. El título hiperbolizado "Coloquio religiosísimo..." funciona para destacar el tema devocional en consonancia con los coloquios espirituales y sacramentales de la época, aunque no embona con la develación espiritual ni con el tratamiento doctrinal de los sacramentos, tal como ocurre en el teatro de Sor Marcela de San Félix (Sabat de Rivers, "Voces del convento"). El segundo

6 Huerta Calvo (Teatro breve 50) y Farré Vidal han considerado a la loa como el género breve que mejor articula ficción y realidad por su lugar en el contexto de la representación: "bisagra entre el público y la ficción escénica” (Farré Vidal, “Sobre loas y festines” 159). 
superlativo del título, “...dedicado al Dulcísimo Nombre de Jesús” (cursivas nuestras), demuestra la influencia de Santa Teresa, quien lo ponía al inicio de todas sus cartas.

La virtud de la obra, importante a la hora de su representación en escena, es introducir a un agente de la ciudad letrada en la caracterización del Licenciado Golondrón Monigote, a quien supuestamente se le encarga escribir el coloquio. En su lugar, el licenciado compone una cuarteta que todos los demás personajes glosan en décimas antes de terminar la obra, donde cada uno desarrollará los dogmas de Jesucristo con alusión al versículo: "Para que al nombre de Jesús doblen las rodillas todos, así los del cielo como los de la tierra y los del infierno" ("Filipenses" 2:10-12). El tema bíblico, especialmente el referente al personaje de Jesús, ha vivido en la tradición oral desde el siglo Xvin. Vicente T. Mendoza aporta varios ejemplos en Glosas y décimas de México (43, 67, 72, 85, 115). Por su parte, Claudia Avilés explica que actualmente el tema bíblico ha sobrevivido en la tradición oral moderna, incluso es uno de los más importantes entre los decimeros de la Sierra Gorda en el estado de Querétaro, donde las décimas están vinculadas a las "fiestas relativas a lo Divino" (175195). Por lo que podemos conjeturar que las composiciones empleadas en este coloquio fueron muy conocidas en la tradición oral de la época.

En la Nueva España, las glosas en décimas fueron aprovechadas "para dar mayor animación a las pastorelas y representaciones de coloquios, en los momentos más dramáticos, utilizándose entonces como modelo aquellas de las obras clásicas españolas" (Glosas y décimas de México 10-11). De las dos corrientes tradicionales de la décima en México, Vicente T. Mendoza ha establecido una clasificación entre las décimas que proceden de los primeros años del régimen hispánico y las que tienen un origen popular, que llegaron con los soldados y oficiales de Carlos III hacia la segunda mitad del siglo XVIII (1765 y 1768) (13; 16). La primera corriente tiene tres momentos claves reconocidos, que aportan una muestra representativa de la diversidad de elaboraciones literarias cuyos frutos se cosecharon gracias a los estímulos oficiales: en el siglo XVI, se encuentran las preguntas y respuestas entre Fernán González de Eslava y Francisco de Terrazas, ca. 1572; en el siglo XVII, el concurso organizado por la Real y Pontificia Universidad de México en 1682, cuyo compendio quedó fijo en el Triumpho parthénico de Sigüenza y Góngora; en el Siglo de las Luces, destaca la beatificación y canonización de Juan de Palafox y Mendoza, donde abundaron composiciones de mayor o menor mérito (14-15). En lo concerniente a la corriente lírica popular, el hecho de haber llegado por la vía militar la dotó de rasgos diversos y variopintos por el contacto entre el pueblo y los soldados, por ejemplo, las canciones con el nombre de "valonas" que fueron enriquecidas con modismos mexicanos (16).

Asimismo, hay un conjunto de décimas de la tradición conventual en el corpus de glosas y décimas mexicanas, que Vicente T. Mendoza ha denominado "Literatura de conventos": un acervo de tres décimas sin glosa que finalizan con una oración dedicada a María; 
INVESTIGACIÓNTEATRAL

Revista de artes escénicas y performatividad

Vol. 9, Núm. 14

octubre 2018-marzo 2019
Personajes y representación en un coloquio conventual novohispano del siglo XVIII

Abel Rogelio Terrazas

otras composiciones, con glosa, están dedicadas al apóstol San Pedro; y unas más, "Para antes de la primera comunión", con el mismo esquema. Hay además un conjunto bastante interesante para nuestro propósito, "Las décimas que ilustran cada una de las pinturas que representan la vida de San Francisco" recogidas en el Convento de Guadalupe, Zacatecas, fechadas entre 1704 y 1721 , donde se glosan las pinturas barrocas del edificio en un total de 19 composiciones (78-88). Glosar los pasajes de la vida de un santo en décimas, para explicar pinturas tiene una función similar, en cierta medida, a la de glosar décimas para fomentar la devoción de las novicias. El funcionamiento general de la décima es eminentemente explicativo, por cuanto la estructura poética permite.

En esta pieza contamos con cuatro décimas religiosas que glosan un tema evangélico: el nombre de Jesús. Podemos ubicarlas en la tradición didáctica conventual de los siglos XVI y XVII; por tanto, son tradicionales en el sentido en que funcionan para alabar y fomentar la devoción de manera sistemática en el convento carmelita. Siguen el esquema métrico de las "espinelas" y tienen como punto de partida una cuarteta, por lo que se trata de una "glosa de cuarteta o decimal, que glosa en cuatro estrofas cada uno de los versos que componen la planta" (Avilés 177). La obra que analizamos es muy breve, por lo tanto, convendrá citar las décimas glosadas en el apartado sobre la caracterización de los personajes.

Los cuatro personajes-tipo glosan la copla:

Es el nombre de Jesús

de los cristianos consuelo,

de los infiernos terror

y la alegría de los cielos (vv. 131-134).

Elvira glosa el primer verso, "Es el nombre de Jesús"; Laura, "de los cristianos consuelo"; la Mulata, "de los infiernos terror"; finalmente, el Licenciado, "y la alegría de los cielos". La cuarteta tiene el modelo de las coplas glosadas en décimas de "Historia religiosa", que continúan vivas en la tradición oral moderna (tales como "Nací de alta jerarquía, / me despeñó mi altivez, / yo vencí al mundo después, / y a mí me venció María”, o "A orillas del río Jordán / se vieron mil maravillas / vide a Cristo de rodillas / bautizándolo San Juan”), cuyas variantes indican que la improvisación podía darles tonos distintivos en cada región del territorio nacional. ${ }^{7}$ El corpus de la lírica tradicional puede enriquecerse con las décimas

7 El repertorio de coplas de la tradición oral moderna puede consultarse en el Cancionero Folklórico de México. Volumen 4. Coplas varias y varias canciones, publicado por Margit Frenk en 1984, donde la investigadora ha brindado una clasificación del repertorio con un número correspondiente; en este caso, la numeración de las coplas citadas es: 8621 y 8622 (13). 
INVESTIGACIÓNTEATRAL

Revista de artes escénicas y performatividad

Vol. 9, Núm. 14

octubre 2018-marzo 2019
Personajes y representación en un coloquio conventual novohispano del siglo XviII

Abel Rogelio Terrazas

de este coloquio, si bien es cierto que la caracterización del licenciado como un escritor de dudosa reputación exime de cualquier error a las composiciones de alabanza. Es decir, las monjas, a través de quien haya escrito este coloquio, están utilizando un motivo paródico entremesil como captación de benevolencia para la loa, que constituye el núcleo escénico y fin devocional del coloquio.

\section{Argumento}

Golondrón Monigote, quien es licenciado y escritor de versos, riñe con una mulata llamada Piltrafa, porque le debe algunos alimentos de su bodegón. Se trata de una riña entremesil entre un hombre de supuesto nivel alto y una mujer del pueblo. El conflicto desnuda la personalidad de cada uno: el licenciado se descubre como un pícaro capaz de robar comida y fingir el oficio de poeta y letrado: “ ¿No adviertes sin desdoro, / que gozo yo el canon y del foro?” (vv. 16-17), presume socarronamente. La mulata, por su parte, resulta ser una mujer práctica, resuelta y valiente porque no duda en restituir la deuda mediante algunas prendas de vestir del supuesto licenciado: "Mi dinero, o la prenda equivalente / he de llevar y más que usted reviente" (vv. 35-36). Cuando la mulata intenta cobrarse con la capa de este sujeto ("que con él pagará mi bodegón", v. 41), dos mujeres -Elvira y Laura- entran para rescatarlo con la promesa de pagar a cambio de que el licenciado haga unos versos o un coloquio para las carmelitas descalzas, como advertimos antes.

El rescate del licenciado es un remanso en medio del conflicto; al parecer, la influencia y prestigio de las carmelitas descalzas es tal que pueden llegar a dirimir conflictos sociales como éste. El dinero fluye de los mecenas hacia las monjas y éstas lo gastan en un divertimento teatral para amenizar el festejo religioso. La risa brota de la doble alusión y, sin embargo, se sostiene el decoro y el valor de las religiosas porque finalmente se escenifica la loa. Piltrafa propone que entre todos ensayen y, una vez convenido, recitan las décimas en alabanza al nombre de Jesús. Lo interesante del argumento es la alusión a las monjas más austeras de la tradición judeocristiana, las carmelitas descalzas, así como el hecho de que se represente su tendencia a solicitar obras de teatro sencillas y acordes con su devoción.

El licenciado representa el círculo de escritores de encargo que rodeaba a los conventos, mientras que el grupo más dilatado de la población analfabeta está representado por la mulata: esclavas libres que vivían con las monjas o en calidad de criadas. La décima funciona para distender la acción violenta entre los tipos que participan en la acción, elemento fundamental para la representación teatral. En el coloquio se muestra cómo el pícaro modela su devoción hacia causas religiosas, ya que antes de ser rescatado por las emisarias de las monjas era un violento bravucón: "Esta perra mulata, esta faraón / intenta desnudarme 
INVESTIGACIÓNTEATRAL

Revista de artes escénicas y performatividad

Vol. 9, Núm. 14

octubre 2018-marzo 2019
Personajes y representación en un coloquio conventual novohispano del siglo XviII

Abel Rogelio Terrazas

sin rencillas, / y me ha hecho ya salir de mis casillas" (vv. 49-51). En efecto, después de la recitación colectiva de las décimas, se restituye el orden social y cada uno de los personajes queda caracterizado por el tema glosado: Tierra, Cielo e Infierno. Las mujeres emisarias son cristianas que reciben consuelo; la mulata quedará vinculada con el infierno, pero redimida; y el licenciado quedará finalmente caracterizado como un compositor celestial de vena popular.

\section{Caracterización de los personajes}

\section{Elvira y Laura}

No están indicadas edades y fisonomías de este par de mujeres; se infiere su pertenencia a una clase social acomodada porque tienen relación con las monjas. Este tipo de mujeres tenían el privilegio de visitar conventos, llevar regalos, cartas y otros documentos como, en este caso, unos versos festivos. Para cumplir con las diligencias se requería madurez y un estado civil honorable. Las visitas se realizaban por las tardes, cuando las monjas habían acabado sus tareas cotidianas, después de asistir a misa y cumplir las oraciones diariamente encomendadas. Como se trata de mujeres allegadas, el lugar propicio para el intercambio de manuscritos sería el locutorio. Lo cierto es que Elvira y Laura no son novicias ni beatas, ya que, en la tradición dramática conventual, las novicias aparecen como tales: Novicia 1, Novicia 2, etcétera. Aunque fueran novicias que todavía no hubieran cambiado sus nombres seculares por los religiosos, el enredo sería inverosímil, como si ambas salieran del claustro con la misión de buscar y encontrarse con el licenciado y la mulata en el bodegón; en este caso, serían beatas. Como amigas de las religiosas, Elvira y Laura demuestran conocimiento de la fe y se expresan con respeto de los asuntos devocionales. Al parecer, buscan cumplir el encargo de las carmelitas y por eso interrumpen el pleito de la mulata y el licenciado:

Aquí mi amiga Laurita claramente me ha insinuado que es usted florido alumno de este Pindo americano, y como soy tan afecta a oír versos bien concertados quiero escuchar los primeros que hace el señor licenciado (vv. 64-71). 
INVESTIGACIÓNTEATRAL

Revista de artes escénicas y performatividad

Vol. 9, Núm. 14

octubre 2018-marzo 2019
Personajes y representación en un coloquio conventual novohispano del siglo XVIII

Abel Rogelio Terrazas

Las mujeres caracterizan al licenciado como un buen compositor, pero la valoración es ambigua porque se trata de su primer ejercicio poético y la mulata lo ha desenmascarado como un pícaro. Por sus parlamentos, Elvira es entendida en poesía y pretende encontrar un poeta "de renombre americano", comparable con el monte Pindo. La cortesía de las mujeres hacia el licenciado es firme y pone orden: "Dejemos ya pataratas / que enfadan en realidad / y pasan de necesidad" (vv. 88-90). Laura demuestra mayor carácter y seriedad, lo que propiciaría mayor desenvolvimiento escénico cuando ambas mujeres unen fuerzas con el objetivo de interrumpir el pleito y cantar alabanzas. Consignan, juntas, un mensaje catequético explícito: dejar la riña para alabar a Jesús. La lección normativa es para reafirmar que la devoción puede alcanzar a mujeres como Elvira y Laura, a gente de pueblo como la mulata y a pícaros y estafadores como el licenciado. La décima de Elvira desarrolla el argumento del nombre de Jesús como un tema devocional de manera ingeniosa:

El nombre que a Dios hecho hombre

dio el cielo con devoción,

asunto es de la cuestión,

pero no es cuestión de nombre

porque el abismo se asombre

y su lóbrego capuz

admire con clara luz

de este nombre el esplendor,

entre todos el mayor

Con Música: Es el nombre de Jesús (vv. 135-145).

El argumento poético juega con la reiteración del tema mediante la dilogía del vocablo cuestión, la Quaestio, del misterio de la encarnación y el dogma que se deriva: "asunto es de la cuestión / pero no es cuestión de nombre". El puente sintáctico atraviesa el campo semántico del abismo, sinónimo de Eternidad, con el fin de subrayar el tema devocional de la segunda redondilla: "porque el abismo se asombre / y su lóbrego capuz". De acuerdo con Guillén Baca, el personaje está resumiendo el dogma de la eternidad del nombre de Jesús, que se encontraba ya en el abismo primigenio de la creación (179). En un nivel escénico, la loa rompe el hechizo entremesil y apunta implícitamente hacia el público receptor de la alabanza, en comunión ceremonial propia del teatro de convento. El acompañamiento musical del verso glosado implica la articulación vocal en consonancia con los instrumentos, posiblemente la vihuela (Muriel, La música). Laura, por su parte, se apoya en el Crátilo de Platón para explicar la hipóstasis del Hijo del Hombre: 
Si el nombre el ser da a entender

(según asienta Platón)

una hipostática unión

Jesús explica en su ser.

De Dios enuncia el placer,

pues con divino desvelo

es el nombre cuyo anhelo

a Dios alegra y complace

y así juntamente se hace

Con Música: De los cristianos consuelo (vv. 145-155).

En esta décima intervienen dos argumentos. El primero consiste en relacionar la hipóstasis de la naturaleza humana y el Verbo divino en una persona, cuya sustancia está en el nombre: "Si el nombre el ser da a entender". El segundo argumento se percibe al final de la décima, en el verso glosado, "De los cristianos consuelo", donde la alabanza se convierte en regocijo para la cristiandad y complacencia para Dios. Por tanto, "y así juntamente se hace", ratifica la doble naturaleza expresada en el nombre, asunto ya argumentado antes, vinculado con la naturaleza humana para su consuelo. Ergo, quienes lo alaban son cristianos. Por lo tanto, la décima de Laura es la más ingeniosa del pequeño certamen poético recreado en el coloquio. Recordemos que esta recreación constituye una alabanza o loa que se articula con la realidad festiva del convento. Aunque Elvira y Laura representan un estatus social elevado, sus décimas son tan semejantes como las de los siguientes personajes-tipo, que representaban lo bajo dentro del código entremesil. Las décimas emparejan a los cuatro en esta segunda secuencia escénica, y si bien todas las composiciones tienen un tono intelectualista, son de raigambre tradicional, puesto que están orientadas por la devoción carmelita. Resulta obvio que la recitación generaría variantes en este convento o en otros, y queda pendiente descubrir y recoger de los archivos esas otras posibilidades.

\section{La Mulata "Piltrafa"}

El vocablo "piltrafa" se usaba para designar la carne magra y las sobras (s.v., Tesoro de la lengua); posteriormente, su significado se amplió para toda aquella cosa que "no tiene más que el pellejo, inútil y asquerosa" (s.v., Autoridades v). Nominalmente, el personaje aparece caracterizado como un despojo o sobra alimenticia, con quien riñe el licenciado y representa, por tanto, no solamente el bodegón de alimentos donde trabaja, sino también el despojo y la pobreza. Una de las funciones dramáticas más importantes de Piltrafa la 
INVESTIGACIÓNTEATRAL

Revista de artes escénicas y performatividad

Vol. 9, Núm. 14

octubre 2018-marzo 2019
Personajes y representación en un coloquio conventual novohispano del siglo XviII

Abel Rogelio Terrazas

Mulata, es proponer la composición de los versos de manera colectiva - por la sencilla razón de contar con cuatro personas el elenco, desde la perspectiva entremesil: ella, el licenciado y las dos mujeres-. Además, su parlamento indica burlonamente que cualquier "animal poético" puede caminar con "cuatro patas", como lo hace el licenciado: "Él siempre habla en cuatro pies, / como el caballo Pegaso" (vv. 76-77), señalando la inhabilidad poética del pícaro en su precario papel de escritor de encargo. Acude, además, al "vulgar adagio", "De médico, poeta y loco / que todos tenemos algo" (vv. 110-120), con el fin de justificar la recitación colectiva. En sus acciones, la mulata se caracteriza como una mujer valiente, lista, práctica e irónica.

En el teatro español, las mulatas poseían un alto contenido erótico y subversivo. En su condición de esclavas, sus rasgos morales franqueaban los límites de la bestialidad. Lope de Vega creó el híbrido entre criada y graciosa cuando recreaba a las mulatas, siempre contestonas, risueñas y capaces de reñir con los hombres. Generalmente sostenían relaciones erótico-afectivas con hombres de su posición social (los criados), pero en algunos casos llegaban a ser interlocutoras del galán y recibían alabanzas y galanteos. Su color de piel era un encanto, símbolo de sensualidad y picardía, un éxito seguro para las representaciones de la época ante un público ávido de exotismo y artificiosidad. En la Comedia Nueva, el personaje se enriqueció gracias a que Lope la dignificó mediante la incorporación del elemento indiano y la transformación de su procedencia africana en americana (Weber 702). Bailes, comidas, oro y plata, la caracterizaron a partir de 1600 como una mujer de procedencia americana, y este modelo es el que triunfará también en el entremés posterior.

Piltrafa Mulata es una mujer valiente; tiene la capacidad de hacer justicia por su propia mano, aunque también amenaza con recurrir al juez como autoridad. En cuanto a inteligencia, despliega en distintos momentos algunas propuestas espontáneas para solucionar el conflicto e incluso es, como advertimos, quien tiene la idea del ensayo poético colectivo para cumplir con el encargo de las monjas. Como negociante de la deuda con el licenciado, se muestra bastante pragmática: “¿Cómo no? ¿Quién tal dijo? / Mi dinero, o la prenda equivalente / he de llevar y más que usted reviente" (vv. 34-36). Durante la ejecución escénica del cobro "en especie", se intensifica la riña con el licenciado y no lo suelta hasta haber asegurado el pago, a juzgar por las réplicas de las mujeres que llegan y pagan por el rescate del pícaro. Posteriormente, se burla de sí misma con el fin de apaciguar la cólera de su oponente: "¿Quién no vio ladrar a las mulas? / Como usted no sabe de chanzas, / no se puede decir cosa / sin que suba la mostaza” (vv. 80-84). Asimismo, se expresa mediante una locución de latín macarrónico durante la riña, con lo que prueba su burla hacia la autoridad que el licenciado ostenta infructuosamente y -justo cuando aquél pretendía golpearla- lo amenaza con su puño: "tenemos cinco dedos en la mano". En seguida continúa: "y casu quo vini vi, ya usted me entiende" (vv. 30; 31). Latín macarrónico que parodia la frase Vini, vide, 
Personajes y representación en un coloquio conventual novohispano del siglo XVIII

Abel Rogelio Terrazas

vinci: vine, vi y vencí, de la época clásica que alude al triunfo del emperador romano Julio César. Con esta frase la mulata sugiere haber vencido porque es capaz de empuñar la mano para defender su propia causa y porque resume jactanciosamente la secuencia escénica.

Piltrafa Mulata también esgrime expresiones del mundo de la oralidad, pues utiliza un refrán desde el principio: "No es razón del contrato / que él los patos se coma y yo / que pague el pato" (vv. 7-9). Se autocaracteriza como una mulata orgullosa, "al óleo", muy adornada y compuesta (s.v., Autoridades), y exige acabar con los ambages: "y no su plata" (v. 15). A la mulata le corresponde glosar el verso, "de los infiernos terror", por lo que la décima reafirma su caracterización como una mujer del pueblo, demoniaca, astuta, pero finalmente domada por la religión:

De Jesús se eleva tanto

el nombre, que admira el hombre

de ser sobre todo nombre,

nombre tan divino y santo:

al infierno le da espanto

este nombre superior,

tiembla al oírlo su rigor,

porque siendo en sí un abismo

viene a ser su alto fracismo

Con Música: De los infiernos terror (vv. 155-165).

Su décima confirma las glosas anteriores, porque expresa y reitera la elevación del nombre divino. La diferencia de su glosa radica en vincular el nombre de Jesús contrastivamente con el infierno, "su alto fracismo", en oposición a la bajeza del abismo infernal que tiembla con sólo oírlo. No es coincidencia haberle correspondido glosar la dimensión infernal que se relaciona con el tema de la canción final, donde Piltrafa reafirma su tema caracterizador: "Nombre tan divino / todos lo bendigan / para que el infierno / abata sus iras" (vv. 183-184).

En suma, la mulata aparece caracterizada como un personaje vinculado con lo demoniaco. Su carácter práctico y astuto, desde el principio, enfatiza su posición social. Algunos elementos cómicos aparecen en el texto espectacular, sobre todo en el desenfado y audacia para resolver el conflicto. Por su posición social de criada y cuidadora del bodegón, su indumentaria (a la usanza de la época) debía proveerla de colores llamativos y vuelo en las faldas, así como de algunas joyas (verdadera oposición dramática frente a la irónica pobreza del licenciado). El aprovechamiento de estos recursos caracterizadores habría podido darle cierta libertad escénica para contonearse al momento de cantar su parte durante la décima y la canción final. 
INVESTIGACIÓNTEATRAL

Revista de artes escénicas y performatividad

Vol. 9, Núm. 14

octubre 2018-marzo 2019
Personajes y representación en un coloquio conventual novohispano del siglo XVIII

Abel Rogelio Terrazas

\section{El licenciado "Golondrón Monigote"}

La función de este tipo en la obra consiste en parodiar lo culto y lo letrado, en contraste con la condición de penuria económica en la que el personaje se encuentra realmente. El licenciado necesita satisfacer su hambre en el bodegón de la mulata y deberá arreglárselas para salir del paso. Su mote, Golondrón Monigote, derivó de dos acepciones antiguas que lo caracterizan como un tipo clásico del teatro breve. En primer lugar, Golondrón significó, desde principios del siglo XVII, quien "parece orgullo y pretensión; y así se dice Don Golondrón, al que toma don (se toma sin causa); y engolondrar, o engolondrinarse, al tomar este orgullo y presunción" (s.v., Origen y etymología). En segundo lugar, su apodo de Monigote se utilizaba para denotar la ignorancia de quienes pretendían adueñarse de una profesión sin saberla, tales como los "legos de las religiones; y por extensión [...] cualquiera otro que juzgan ignorante de su profesión" (s.v., Autoridades IV). Con esta caracterización nominal se infiere cómo el tipo que asume la máscara tradicional del licenciado, ya presente en la cultura literaria hispánica: "Se llama vulgarmente al que viste hábitos largos o anda en trage de estudiante" (ibid.).

En escena, se exhibe como un tipo temerario ante la solicitud de las carmelitas descalzas, en su atrevimiento de pretender cumplir con una obra de encargo. Golondrón Monigote es un tipo dramático contradictorio, presuntuoso por un lado y falso por el otro. Su condición es paradójica porque alberga en su personalidad dos dimensiones psicológicas contrarias. Orgullo e ignorancia constituyen un gesto de deformación moral muy propia de los abogados que manipulaban la ley a su antojo para alcanzar sus propios intereses. Los licenciados, en el mundo social de los Siglos de Oro, cuidaban en extremo su apariencia, como era costumbre entre quienes pretendían destacar su posición frente a los demás (Salazar Rincón 44). En el teatro breve aparecen caracterizados por el fingimiento de credenciales y la picardía, lo que los vincula con los bachilleres. Tras la fundación de las universidades y el auge del mundo escolar en la península, abundaron estudiantes de "malas mañas". Corneja, criada en el entremés La venta, de Francisco de Quevedo, caracteriza a un estudiante con ironía: "El señor bachiller no peca en berros"; ${ }^{3}$ a lo que el Estudiante replica con burla: "Ni el señor Licenciado zape en perro" (vv. 56; 57). La equiparación moral y social entre licenciados y bachilleres se hacía notar. En efecto, en el entremés de Quevedo el estudiante acude a la venta con la finalidad de comer y la criada sabe muy bien de la fama de insolvencia por parte de tales personajes.

8 Según el Tesoro de la lengua castellana o española, de Sebastián de Covarrubias, "darse al berro" era "darse al vicio". 
Personajes y representación en un coloquio conventual novohispano del siglo XVIII

Abel Rogelio Terrazas

Golondrón comete robos por hambruna y se codea con los marginados. El licenciado es en realidad un mal estudiante, un pícaro capaz de estafar: ha comido sin pagar y además es peleonero y leguleyo. También es violento y colérico, pues se dirige a la mulata con patadas: "No adviertes sin desdoro, / que gozo yo del canon y del foro? / ¡Ea, vete noramala, / no sea que si me enfadas / te dé un repelón y mil patadas!" (vv. 16-20). Se defiende mediante la presunción de títulos, del dominio del canon y, sobre todo, vocifera ser influyente entre los jueces. No obstante, decide quitarse la máscara de sabio letrado porque la mulata se muestra inmune ante las petulancias e incluso ante la amenaza de ser golpeada: "Tu retobo en más cólera me enciende / y en fin, para despacharte, te pre- / vengo / que con nada te pago porque nada / tengo" (vv. 32-34). Finalmente, cambia de personalidad en presencia de las dos mujeres, Elvira y Laura, cuando llegan con la promesa de sacarlo del apuro: "Ustedes no hagan caso del acaso / y mándenle a su criado en todo caso" (vv. 63-64), dice en tono zalamero y melodioso. El licenciado Golondrón exhibe falta de profesionalismo, incluso cuando proyecta la idea del coloquio solicitado: "Aunque no es arte ni ciencia / la poesía, según Lactancio, / a usted serviré gustoso / con versos de pie quebrado" (vv. 72-75). El resultado son las décimas que entre todos los presentes cantan y terminan ingeniosamente con el verso correspondiente de la copla glosada: "Nos dé la letra, / y está en décimas trovando / sea el encomio de la idea" (vv. 123-125), como propone la mulata. El despliegue coral de los cuatro personajes transcurre conforme la promesa del licenciado. Como antes señalamos, el licenciado glosa el último verso, "y la alegría de los cielos", por lo que se vincula con lo más alto. En su glosa, despliega la alabanza del gozo celestial, de los ángeles hacia el nombre de Jesús y resume las glosas anteriores, de Elvira, Laura y Piltrafa, además de la suya:

Se postran reverenciales

al oír nombre tan profundo

los moradores del mundo

y vivientes celestiales.

Aun hasta a los infernales

les da este nombre desvelos, pues dando al mundo consuelos, es de los ángeles gozo, de lo criado, alborozo.

Con Música: Y la alegría de los cielos (vv. 165-175).

Golondrón no explica ni desarrolla el argumento poético de su verso glosado, más bien enfatiza la alabanza y las virtudes del nombre de Jesús en la Tierra y en el infierno. En el texto espectacular, por el hecho de resumir las décimas de los demás personajes, alude 
INVESTIGACIÓNTEATRAL

Revista de artes escénicas y performatividad

Vol. 9, Núm. 14

octubre 2018-marzo 2019
Personajes y representación en un coloquio conventual novohispano del siglo XviII

Abel Rogelio Terrazas

a que los cristianos consolados por el nombre de Jesús son Elvira y Laura, mientras que el terror de los seres infernales en el abismo encarna en la Mulata. No hay didascalias deícticas para aseverar el señalamiento de Golondrón hacia cada una de las mujeres en el escenario. Sin embargo, es posible inferir la función del licenciado como organizador del "certamen" y que el señalamiento está implícito en los campos semánticos desarrollados por cada uno de los personajes en sus respectivas décimas. Una vez que todos han glosado sus composiciones, continúan con una canción en hexasílabos que anuncia el fin de la representación. El tono grandilocuente de la décima glosada queda atrás gracias a las cuartetas de estilo claro y directo: "Sea gloria de Dios / el nombre que explica / de las tres personas / la esencia divina” (vv. 187-190). La cuarteta, de tono sencillo y popular, crea una atmósfera festiva y de no-competencia. Por su estructura rítmica, su función es eminentemente musical como las coplas del folclor mexicano, "Clavadas al cielo / tus sienes divinas / con barras de juntos / y agudas espinas” (Frenk 27). La violencia de Golondrón ha quedado muy atrás, cuando realizaba y asumía el papel de poeta. Finalmente, canta y convive con sus semejantes.

Como se observó, las décimas funcionan para caracterizar a los personajes y constituyen una loa dentro del coloquio, lo que permite establecer una atmósfera festiva y distender la acción dramática inicial del pleito entremesil, cuando reñían acaloradamente. Además, la pieza contiene al final unas coplas cuya versificación oscila entre las cinco y siete sílabas, que reafirman el campo semántico glosado por cada personaje en sus respectivas décimas. Por ejemplo, la cuarteta de Elvira, "Sea tan alto el nombre / colmo de las dichas / y lo alaben siempre / las voces empíreas" (vv. 175-178), concuerda con la glosa del verso, "Es el nombre de Jesús". La cuarteta de Laura, “Toda criatura / se muestre expresiva / aplaudiendo amante / tan sagrada cifra" (vv. 179-182), concuerda con la glosa, "De los cristianos consuelo". La mulata y el licenciado, como se vio antes, también hacen corresponder sus coplas con las décimas glosadas. En conjunto, coplas y décimas son vehículos para el mensaje devocional desde dos ángulos complementarios. Primero desde una perspectiva didáctica, y enseguida festiva y de rápida acción escénica. Los vehículos del mensaje funcionan como anzuelos para cautivar a un público mixto, conocedor de décimas y coplas tradicionales, acostumbrado a escucharlas en ambientes festivos, certámenes, lecturas orales colectivas y versificaciones improvisadas. El efecto de las coplas en los parlamentos finales, entre una, dos y tres voces intercaladas, refrendan el mensaje de convivencia festiva:

Golondrón Sea gloria de Dios el nombre que explica de las tres personas la esencia divina. 
INVESTIGACIÓNTEATRAL

Revista de artes escénicas y performatividad

Vol. 9, Núm. 14

octubre 2018-marzo 2019
Personajes y representación en un coloquio conventual novohispano del siglo XVIII

Abel Rogelio Terrazas

\author{
ELVIRA Y en los corazones \\ tal nombre se imprima, \\ LAURA para que las almas \\ se muestren gratuitas, \\ Piltrafa Repitiendo alegres. \\ Golondrón diciendo festivas. \\ Todos que tan alto nombre \\ triunfe, reine y viva. (vv. 187-195)
}

\title{
Conclusiones
}

La ciudad letrada expresó su función en este convento de monjas: escribir para la devoción de las novicias, instruirlas ingeniosamente a través de recursos tradicionales como las décimas y amenizar la ceremonia con un cierre festivo. De acuerdo con el análisis previo, el escritor de encargo se integra paródicamente en el convento y conviene ideológicamente a la causa monárquico-clerical: pícaros y arrebatacapas quedarán subsumidos en el orden de los signos, gracias a las monjas y sus devociones interiores, que son capaces de articular el cuerpo social del exterior. El vínculo o bisagra con ese mundo exterior está representado diegéticamente por las mujeres comisionadas, pero también escénicamente por la loa, conforme el curso del festejo. Con base en las caracterizaciones, podemos afirmar que los personajes siguen la tradición hispánica del entremés barroco. No diluyen sus características genéricas, las reafirman y concretizan en el momento de hacerlas reconocibles para un público local. No obstante, según observamos, en el caso de la mulata tenemos a un personaje bien arraigado en el suelo americano. Surgida de África como personaje, recrea el suelo americano con un semblante cómico: sus alusiones son burlonas, pero atractivas, porque proceden de un mundo mestizo e híbrido. En esta obra, la mulata incursionó en el certamen poético con una décima en el mismo nivel escénico que los demás; ha cumplido cabalmente su papel y reivindica un lugar — que ella misma buscó- desde el momento de proponer el ejercicio poético de manera colectiva. En la Comedia Nueva había una función tópica entre los temas de las canciones y la clase social de los personajes que las cantaban. La décima de la mulata es el modelo idóneo para incorporar, en el espectáculo, la representación social de una casta de cuño exótica y picante.

En el caso del licenciado, resulta claro que su presencia era atractiva porque funcionaba como advertencia moral sobre la presencia y abundancia de pícaros en la capital del virreinato. El pícaro era un tipo para hacer reír y fustigar, descubriendo las relaciones 
Personajes y representación en un coloquio conventual novohispano del siglo XVIII

Abel Rogelio Terrazas

entre el convento de monjas y los estudiantes a quienes posiblemente encargaban versos de entretenimiento. Hay indicios, en esta obra, de que las monjas no seguían estrictamente la Regla. Por ejemplo, no era posible que organizaran un certamen poético e invitaran poetas (hombres) al interior de los aposentos. Con esta pieza, sin embargo, pudieron "introducir" la fiesta mediante la loa en décimas. Las monjas habían descubierto la vena joco-seria y la veta paródica, no para abundar en temas sacros y la enseñanza del evangelio, sino para promover modelos de conducta. La representación de esta pieza implica que las monjas tenían una idea clara de cómo, solamente así, podían sostener la atención de un público mixto compuesto por su propia comunidad y las visitas externas. Por tanto, la lección moralizante se sobrepone al adoctrinamiento religioso y, como consecuencia, tenemos aquí un entremés conventual articulado con una loa religiosa. El análisis previo nos permite plantear que la morfología entremesil que aporta la pieza es la integración: el motivo cómico subsumido en el coloquio y armonizado con el cierre festivo. La sección entremesada no es relativa al tema de la loa, pues el pleito por la comida de ninguna manera embona con el tema devocional. El contraste configura la obra y depende de la ceremonia religiosa donde se integraba. Por tanto, la loa justifica la presencia del entremés profano en el claustro.

\section{Bibliografía}

Adorno, Rolena. "La ciudad letrada y los discursos coloniales". Hispamérica, vol. XVI, núm. 48, 1987, pp. 3-24.

Alarcón, María del Carmen. "El teatro como didáctica de la santidad. El Diálogo que representaron las carmelitas descalzas de Toledo en la vela de la Madre Ana de San José. Año de 1660". Medievalia, núm. 18, fascículo 2, 2015, pp. 247-272.

Arellano, Ignacio. "La risa en las comedias jesuíticas sobre San Francisco Javier". São Francisco Xavier: nos 500 anos do nascimento de São Francisco Xavier: da Europa para o mundo 1506-2006. Oporto: Centro Interuniversitário de História da Espiritualidade, 2007, pp. 7-26.

Arellano, Ignacio y Andrés Eichmann, eds. Entremeses, loas y coloquios de Potosí: (colección del convento de Santa Teresa). Madrid: Universidad de Navarra-Editorial Iberoamericana-Archivo y Biblioteca Indiana, 2005.

Avilés Hernández, Claudia. "La décima popular escrita: una descripción temática del cuaderno del trovador Antonio Escalante Hinojosa”. Literatura de tradición oral de México: géneros representativos. Ed. Donají Cuéllar Escamilla. Xalapa: El Colegio de San Luis/ Universidad Veracruzana, 2012, pp. 175-195. 
Castro Gómez, Santiago. "Los vecindarios de la ciudad letrada. Variaciones filosóficas sobre un tema de Ángel Rama”. Ángel Rama y los estudios latinoamericanos. Ed. Mabel Moraña. Pittsburgh: Universidad de Pittsburgh, 2006, pp. 123-136.

Ciudad Real, Antonio de. Tratado curioso y docto de las grandezas de la Nueva España. México: UNAM, 1976.

Covarrubias, Sebastián de. Tesoro de la lengua castellana o española. Madrid: Imp. Luis Sánchez, 1611. Reproducido a partir del ejemplar de la Biblioteca de la Real Academia Española. En línea. Consultado el 20 de abril de 2018.

De la Campa, Román. "El desafío inesperado de La ciudad letrada". Ángel Rama y los estudios latinoamericanos. Ed. Mabel Moraña. Pittsburgh: Universidad de Pittsburgh, 2006, pp. 29-54.

Farré Vidal, Judith. Festín plausible con que el convento de Santa Clara celebró en su felice entrada a la Ex.ma D. María Luisa, condesa de Paredes, marquesa de La Laguna y Virreina de esta Nueva España. México: El Colegio de México, 2009.

Farré Vidal, Judith. "Sobre loas y festines o el elogio a las virreinas en la Nueva España durante la época de Carlos II". Teatro y poder en la época de Carlos II. Fiestas en torno a reyes y virreyes. Ed. Judith Farré Vidal. Madrid: Universidad de Navarra/Iberoamericana-Vervuert, 2007, pp. 117-132.

Frenk, Margit. Cancionero folklórico de México. Coplas varias y varias canciones. México: El Colegio de México, 1984.

Gage, Thomas. Nueva relación que contiene los viajes de Tomas Gage en la Nueva España. Guatemala: Tipografía Nacional, 1946.

Guillén Baca, Víctor Jesús. "Ocho piezas devocionales inéditas del teatro carmelita (siglos XVIII-XIX)”. Tesis de licenciatura, Universidad Nacional Autónoma de México, 1995.

Huerta Calvo, Javier. Teatro breve de los siglos XVI y XVII. Entremeses, loas, bailes, jácaras y mojigangas. Madrid: Taurus, 1987.

Lavrin, Asunción y Rosalva Loreto López. Diálogos espirituales. Manuscritos femeninos hispanoamericanos. Siglos Xvi-Xıx. Puebla: Universidad de las Américas, Puebla / Benemérita Universidad Autónoma de Puebla, 2006.

Luciani, Frederick. "Fantasmas en el convento: una 'máscara' en San Jerónimo (México, 1756)”. El teatro en la Hispanoamérica colonial. Eds. Ignacio Arellano y José Antonio Garrido. Madrid: Iberoamericana Editorial / Vervuert, 2008, pp. 259-273.

Martínez Cuesta, Ángel. "Las monjas en la América Colonial. 1530-1824”. Thesaurus, tomo L, núms. 1, 2 y 3, 1995, pp. 572-626.

Martínez López, María José. "Estudio comparativo de los personajes del teatro breve: del entremés al sainete". Lenguaje y textos, núm. 10, 1997, pp. 159-172. En línea. Consultado el 7 de enero de 2018. 
Mendoza, Vicente T. Glosas y décimas de México. México: Fondo de Cultura Económica, 1957.

Moraña, Mabel, ed. Ángel Rama y los estudios latinoamericanos. Pittsburgh: Universidad de Pittsburgh, 2006.

Moraña, Mabel. Políticas de la escritura en América Latina. De la colonia a la modernidad. Caracas: eXcultura, 1997.

Muriel, Josefina. La música en las instituciones femeninas novohispanas. México: Universidad Nacional Autónoma de México, 2009.

Muriel, Josefina. Conventos de monjas en la Nueva España. México: Editorial Santiago, 1946.

Parodi, Claudia. “Teatro de monjas en Nueva España”. Biblioteca Virtual Miguel de Cervantes, 2002. En línea. Consultado el 29 de marzo de 2018.

Parodi, Claudia. "Las obras menores". Obra dramática: teatro novohispano del siglo XVIII. Ed. Cayetano Cabrera y Quintero. México: Universidad Nacional Autónoma de México, 1976, pp. XLVI-LIII.

Picón Salas, Mariano. De la Conquista a la Independencia: tres siglos de historia cultural latinoamericana. México: Fondo de Cultura Económica, 1944.

Quevedo, Francisco de. Teatro breve del Siglo de Oro: entremeses y loas. Madrid: Penguin Clásicos, 2016.

Rama, Ángel. La ciudad letrada. Hanover: Ediciones del Norte, 1984.

Rama, Ángel. "La señal de Jonás sobre el pueblo mexicano". La crítica de la cultura en América Latina. Caracas: Biblioteca Ayacucho, 1980, pp. 19-65.

Ramos Smith, Maya. Censura y teatro novohispano (1539-1822). Ensayos y antología de documentos. México: Instituto Nacional de Bellas Artes - Centro Nacional de Investigación, Documentación e Información Teatral Rodolfo Usigli, 1998.

Real Academia Española. Diccionario de Autoridades. Madrid: Imp. Francisco del Hierro, 1726-1739. En línea. Consultado el 1 de abril de 2018.

Rivera Krakowska, Octavio y Abel Rogelio Terrazas. "Comunidades, monjas y teatro en Nueva España, siglo xviı". Investigación Teatral, vol. 6, núm. 9, 2016, pp. 27-44.

Romero de Terreros, Manuel. Bocetos de la vida social en la Nueva España. México: Porrúa, 1944.

Rosal, Francisco del. Origen y etymología de todos los vocablos originales de la Lengua Castellana.1611. En línea. Consultado el 17 de marzo de 2018.

Sabat de Rivers, Georgina. "Voces del convento: Sor Marcela, hija de Lope". Actas del IX Congreso de la Asociación Internacional de Hispanistas, Berlín, 1986. Centro Virtual Cervantes, pp. 591-600. En línea. Consultado el 17 de febrero de 2018.

Salazar Rincón, Javier. El mundo social del Quijote. Madrid: Gredos, 1986. 
INVESTIGACIÓNTEATRAL

Revista de artes escénicas y performatividad

Vol. 9, Núm. 14

octubre 2018-marzo 2019
Personajes y representación en un coloquio conventual novohispano del siglo XviII

Abel Rogelio Terrazas

Sten, María y Raquel Gutiérrez Estupiñán. No solo ayunos y oraciones. Piezas teatrales menores en conventos de monjas (siglo XVIII). México: Universidad Nacional Autónoma de México / Benemérita Universidad Autónoma de Puebla, 2007.

Sosa, Francisco. "El Ilmo. Sr. D. Manuel José Rubio y Salinas (1749-1765)". El Episcopado Mexicano. México: H. Iriarte y S. Hernández, 1877, pp. 181-191. En línea. Consultado el 30 de septiembre de 2018.

Valera, Cipriano de. El Nuevo Testamento de Nuestro Señor y Salvador Jesucristo. Versión de Cipriano de Valera, revisada y correg. Nueva York: Sociedad Bíblica Americana, 1923.

Weber de Kurlat, Frida. "El tipo del negro en el teatro de Lope de Vega: tradición y creación”. Actas del II Congreso de la Asociación Internacional de Hispanistas, Nijmegen, 1965. Centro Virtual Cervantes, pp. 695-704. En línea. Consultado el 17 de febrero de 2018. 